\title{
Employing the Precautionary Principle to Evaluate the Use of E-Cigarettes
}

\author{
Ashley M. Bush ${ }^{1 *}$, James W. Holsinger Jr. ${ }^{2}$ and Lawrence D. Prybil ${ }^{1}$ \\ 'Department of Health Management and Policy, University of Kentucky, Lexington, KY, USA, ${ }^{2}$ Department of Preventive \\ Medicine and Environmental Health, University of Kentucky, Lexington, KY, USA
}

Electronic cigarettes (e-cigarettes) have emerged onto the public market as an alternative to tobacco cigarettes; however, science is inconclusive as e-cigarettes have not been thoroughly investigated, including their short- and long-term risks and benefits $(1,2)$. The question arises of whether e-cigarettes will become the future tobacco crisis. This paper connects the precautionary principle to the use of e-cigarettes in an effort to guide decision-makers in the prevention of adverse health outcomes and societal costs.

Keywords: precautionary principle, e-cigarettes, tobacco, smoking, public health

\section{OPEN ACCESS}

Edited by:

Colette Joy Browning,

RDNS Institute, Australia

Reviewed by:

Aida Mujkic,

University of Zagreb, Croatia

Armin D. Weinberg,

Rice University, USA and Texas A\&M

University, USA

*Correspondence:

Ashley M. Bush

ambush2@uky.edu

Specialty section:

This article was submitted to Public Health Education and Promotion,

a section of the journal

Frontiers in Public Health

Received: 24 September 2015

Accepted: 12 January 2016

Published: 04 February 2016

Citation:

Bush AM, Holsinger JW Jr. and Prybil LD (2016) Employing the Precautionary Principle to Evaluate

the Use of E-Cigarettes.

Front. Public Health 4:5.

doi: 10.3389/fpubh.2016.00005

\section{USING THE PRECAUTIONARY PRINCIPLE TO EVALUATE THE USE OF E-CIGARETTES}

Electronic cigarettes (e-cigarettes) are marketed as a smoking cessation tool, and their use is increasing particularly among middle and high school students in the US, but among adults as well (3, 4). Despite the high prevalence of use, e-cigarettes have not been thoroughly investigated (5); the benefits and risks of their use are unknown, including the chemicals being consumed (1). Voluntary consumer and health-care reports cite hospitalization for pneumonia, seizures, disorientation, congestive heart failure, and hypotension as e-cigarette related (5). However, studies so far show mixed evidence, including no significant relationship regarding smoking cessation and e-cigarettes $(6,7)$ and potential for cessation $(8,9)$, while others suggest e-cigarettes encourage "dual use" in conjunction with smoking tobacco $(3,10,11)$. The adoption of e-cigarettes is strongly promoted; e-cigarettes are advertised on radio and television, and in print as occurred in the 1950s with tobacco (3).

Although other ethical principles are available, this paper utilizes the precautionary principle $(\mathrm{PP})^{1}$ in considering the issue of the use of e-cigarettes. This principle may be utilized in an effort to increase protection and to minimize risk from harmful activities, such as e-cigarette use, in an effort to prevent another nicotine crisis. The PP is used to guide decision-making when science is inconclusive and forces individuals to promote "the greatest good for the greatest number" (16). The $\mathrm{PP}$ encourages planning, precaution, and prevention rather than a reaction to harmful activities. In recent years, the PP has been cited in national legal codes and international treaties, as well as having been utilized by commercial organizations to describe potential harm from products (14, 17-19).

\footnotetext{
${ }^{1}$ Raffensperger and Tickner (12); Martuzzi and Tickner (13); Wingspread Statement on the Precautionary Principle (14); O'Riordan and Cameron (15). Authoritative sources. Subsequent sections of this paper will discuss its application to electronic cigarettes and America's health.
} 


\section{CONSIDERATION OF CIGARETTE USE AS A FAILED PUBLIC HEALTH POLICY}

Tobacco production and consumption have resulted in what Fink defines as a crisis (20). A crisis has four stages: (1) prodromal, (2) acute, (3) chronic, and (4) resolution (20). As early as the 1950s, warning signs (prodromes) were present regarding the use of tobacco (20) as scientific studies of smoking and its adverse health effects were being published (21), prompting a US government response in an effort to prevent the impending crisis. "Smoking and Health," a report by the Surgeon General's Advisory Committee, indicated the harmful effects of smoking. The Report quotes US Surgeon General Leroy E. Burney, who stated in 1957 that "excessive smoking is one of the causative factors of lung cancer." The Report referred to Burney's 1959 article in the Journal of American Medical Association, which stated that "smoking is a principal factor in the increased incidence of lung cancer" and increases lung cancer risks. Meanwhile, tobacco companies' industry-sponsored research examining the effects of smoking on laboratory animals was inconclusive (21). Some commentators have thought that the tobacco industry manipulated or withheld results to maximize earnings (22-24).

Despite these warnings and research, the production and use of smoking tobacco continued, with the tobacco industry refining its traditional marketing practices. It began offering filtered, low-tar and nicotine options, coupons, and sponsorships (e.g., concerts, sporting events, and other promotions) to increase cigarette consumption. Almost two decades passed following the first studies before product labeling was required, and radio and television advertising were banned to help decrease overall cigarette consumption $(25,26)$.

Following the warning signs of the first crisis, the tobacco industry worked to control communication - a key to good crisis management (20). Their efforts were visible in their marketing of tobacco products, which helped to thwart legal action against the industry. Tobacco companies developed a Tobacco Industry Research Committee to combat claims regarding adverse outcomes from tobacco use $(22,27)$. Some hypothesize that the warning signs were the reason that the tobacco industry invested in the international market and various varieties of cigarettes (26).

The acute phase evolved - "the point of no return" (20) - after the tobacco companies' 1994 Congressional testimony. At this time, the tobacco industry's communication began to unravel as the CEOs of seven largest tobacco companies publicly stated that cigarettes were not addictive, statements contrary to a former tobacco company board member's 1963 claim that "Nicotine is addictive. We are, then in the business of selling nicotine, an addictive drug" (28). This resulted in "misunderstanding and [the] erosion of trust" among the tobacco companies' constituents (29). Prior to this time, the tobacco companies groomed their positive public image and gained the trust of consumers, as well as increased their profitability. This brief phase led to further investigation by the various parties involved, with the resulting transition to the chronic crisis phase.

In the chronic phase, public health agencies, government entities, and tobacco companies all tried to control the tobacco crisis through litigation. After the CEOs' testimonies, information regarding the actual long-term effects of smoking was made available. Tobacco was determined to be the leading cause of preventable death in the US. In this situation, the efforts made to control the repercussions of the tobacco crisis were carried out by public health agencies, the various states, and individuals by holding the tobacco companies accountable for their product - cigarettes. In 1998, these efforts led to the $\$ 206$ billion Master Settlement Agreement (30).

The tobacco crisis is currently in the chronic phase, such as beginning January 1, 2016, Hawaii will become the first US state to raise the legal purchasing age of cigarettes to 21 years (31). In actuality, the Institute of Medicine reports that raising the national minimal legal age to 21 could help prevent 223,000 premature deaths, 50,000 deaths from lung cancers, and over 4 million years of life lost for persons born from 2000 to 2019 (1). Medical costs continue to rise as tobacco-related diseases, and mortality rates remain high with the overall mortality three times greater for smokers than those who have never smoked (32). Thus, tobacco-related diseases are still the most preventable cause of death in the US (32). Smoking-related costs were \$289 billion from 2009 to 2012, of which $\$ 133$ billion provided direct medical care and $\$ 156$ billion was based on smoking-related lost productivity (32). Although the tobacco industry spent $\$ 8$ billion in cigarette marketing in 2011 (32), the use of tobacco is still a winnable public health battle (32).

\section{A BRIDGE BETWEEN A PAST AND NEW PUBLIC HEALTH PROBLEM}

The tobacco crisis exemplifies the need for improved policies to address smoking, a past public health problem, and e-cigarettes, a new public health problem. The PP provides an effective approach, utilizing an upstream methodology to reduce harm to humans and the environment. The principle was developed in the 1930s (15), and it is derived from the German word Vorsorgeprinzip, which means forward looking (12). Prior use of the principle included the creation of legislation regarding water pollution, natural resource exploitation, and toxic substance use (12, 19, 33). The PP states,

When an activity raises threats of harm to human health or the environment, precautionary measures should be taken even if some cause and effect relationships are not fully established scientifically. In this context the proponent of an activity, rather than the public, should bear the burden of proof. The process of applying the Precautionary Principle must be open, informed and democratic and must include potentially affected parties. It must also involve an examination of the full range of alternatives, including no action (Wingspread Statement on the Precautionary Principle, 1998) (14).

Moreover, the PP originated as a link between "uncertain scientific information and a political responsibility ... [in order] to prevent damage to human health" (13). 


\section{Advantages of the Precautionary Principle}

The PP has been both praised and criticized. Proponents praise it because it protects individuals, who may require policy efforts to control exposure and limit risk due to their vulnerabilities and/or inability to change exposures. It calls for persons to use common sense when science is uncertain or absent (i.e., if a product appears to be negatively affecting the environment or individuals, use should diminish or cease while alternatives are explored). Scientific evidence does not always advance quickly enough to establish absolute cause and effect due to uncertainty (i.e., it takes time to understand the long-term effects of tobacco use). Acknowledging this, the PP suggests that actions should be undertaken to prevent further harm to an increasing number of individuals during this period of uncertainty.

The PP calls for an examination of the activity of interest using a socioecological perspective (34), where individuals, industry, and policy-makers work together to understand the problem [e.g., Socioecological Model - Figure 1 (34)]. It calls for industries to wait to introduce products to society until they are able to demonstrate minimal risk. Also, the PP appeals for a more educated populace, resulting in informed stakeholders who are then able to exercise autonomy in risk-taking. Citizens desire the ability to choose, even if their choices are irrational. By promoting open and democratic decision-making, "group think" is limited (35). Different perspectives are considered, which can lead scientists, policy-makers, and the public to think outside of the norm. Finally, the PP spurs the quest for safer alternatives that may expand the use sustainable and reusable products in order to reduce harm.

\section{Criticisms of the Precautionary Principle}

Critics state that the PP has economic consequences in that it limits industrial production and time and causes the loss of jobs, thus creating financial hardship for workers and their families. Precautions may result in presumptions concerning an activity's effect and stigmatize the activity prior to scientific studies being undertaken (i.e., premature conclusions). Some investigators suggest that "false-positives" will occur and distract focus and resources away from the actual burden of

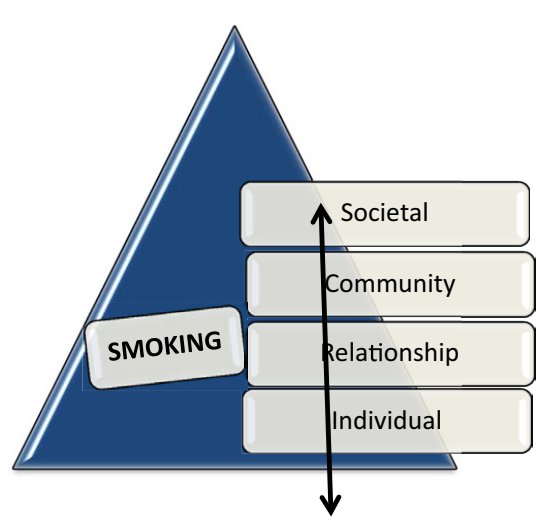

FIGURE 1 | Sociological model. Adapted from the Framework for Prevention and Protection (34). the undertaking (36). Critics also argue that the PP is too conservative as it encourages bans on products when only slight exposure and/or harm exist.

Discussion and debate have centered on the lack of a universal operational definition of the PP, which may complicate when and how the principle is exercised (37). Detractors also state that the PP suppresses innovation and technology (38), and scientists argue that it encourages decision-making without scientific support (38). Because the PP pushes science inquiry, when feasible, for justification in the use of certain products or activities, a misuse or misunderstanding of the science by policy-makers and industry may occur. Even though the PP calls for all parties to be informed, scientists and industry leaders may sanction products as safe based on their findings but may not reveal study results in their entirety.

\section{APPLICATION OF THE PRECAUTIONARY PRINCIPLE TO E-CIGARETTES TO ADDRESS AN IMPENDING PUBLIC HEALTH CRISIS}

The tobacco crisis justifies the current application of the PP to e-cigarette use. E-cigarettes are devices that deliver nicotine to the body with vaporized delivery mechanisms that were introduced to the US market in 2004. Currently, although e-cigarettes are regulated by the Food and Drug Administration (FDA), research on risks and benefits of their use is scant. The FDA found that some e-cigarettes contain known carcinogens (e.g., anabasine, nitrosamines, diethylene glycol, etc.) (2). However, the FDA stated that conclusions cannot be drawn due to product variability (2). Research has revealed 466 different e-cigarette brands in the US (39). In fact, US researchers examined one e-cigarette brand and found nanoparticles, silicate beads, and metals (lead, nickel, and chromium) in the aerosol vapor and cartomizer fluid (40). These metals have a well-documented history of causing lung (e.g., impaired function, cancer, respiratory irritation, and pulmonary fibrosis), nervous system, and kidney damage when inhaled and/or digested (40).

Implementation of the PP may prevent deleterious health effects in the future through research and regulation of these untested devices. A looming concern is that nicotine, fruit flavorings, and other e-cigarette additives may encourage teenagers and children to initiate use of tobacco cigarettes (41). The American Academy of Pediatrics (2013) stated that children may decide to use e-cigarettes because they are perceived to be safer than conventional cigarettes (41). The CDC found that 1.8 million middle and high school students have tried e-cigarettes (42). The age of smoking initiation is basic to the argument that smoking is a "pediatric disease" (43). Additionally, adolescent e-cigarettes users were more likely over the next year to smoke tobacco than non-users (11). Some states are exercising the PP through proactive legislation by prohibiting e-cigarette sales to minors (e.g., Kentucky) (44), raising the minimum age limits for purchasing e-cigarettes to 19 (e.g., Alaska) and 21 (e.g., New York City) (1), and amending existing smoking bans to include e-cigarettes (e.g., New Jersey) (44). Nonetheless, e-cigarettes may be purchased in other states and from online 
retailers without age restrictions; thus, permitting children and teenagers to obtain e-cigarettes and initiate their use.

Ethically speaking, the PP encourages accountability, transparency, and responsibility from the e-cigarette industry for their products. The PP urges policy-makers to move away from a policy based on presumption of innocence until proven guilty for activities and products to one that is based on the finding of guilty until proven innocent. Should e-cigarettes be regarded as dangerous until proven safe? Should the e-cigarette industry be required to prove that its products are free of risk to humans?

\section{A RETROSPECTIVE APPLICATION OF THE PRECAUTIONARY PRINCIPLE TO THE TOBACCO CRISIS}

Scientific inquiry early established the consequences of smoking tobacco; however, American society allowed politics and the tobacco companies to dictate action in this instance. The tobacco industry failed to accept the scientific evidence - studies showing a causal relationship between smoking and cancer. Questionable decision-making by all parties allowed the crisis warning signs to intensify with time, as did the ill health effects of cigarette use.

Although introduced to the US in 1998, the PP, relying on scientific evidence, may have helped to alleviate or prevent the impact of the tobacco crisis. As early as 1950, scientific research was initiated to understand the effects of tobacco use. On the other hand, tobacco manufacturers countered these scientific efforts by claiming that its own research demonstrated no causal relationship between smoking and health. The first scientific studies in conjunction with the Surgeon General Reports should have resulted in "bright spots" for the government and public as the health risks of tobacco consumption were demonstrated (45). Public health agencies acted on the reports by requiring cigarette labeling and television-advertising bans, but despite these efforts tobacco sales increased in the mid-1970s (25). Utilizing the PP may have guided leaders to examine alternatives that would result in minimizing harm for the greatest good and that would expedite the process of protecting the public. However, even today, over 3,200 children initiate smoking cigarettes daily (32). Policymakers were puzzled as to how to regulate cigarettes since they were considered neither food nor drug and the effects of smoking could not be observed until decades later. For this reason, utilizing the PP could have proved useful as further understanding of the effects of tobacco use would have been required, potentially preventing progression into the acute crisis stage.

The PP results in a search for alternative products or practices to achieve similar benefits from cigarette use (e.g., stress reduction). The PP could have discouraged the use of harmful chemicals in cigarettes, and encouraged development of other means of nicotine delivery. Currently, the Patient-Centered Outcomes Research Institute (PCORI) is conducting comparative research on the effectiveness of smoking cessation compared to long-term nicotine replacement therapy for high-risk individuals. Study findings may provide evidence to support nicotine alternatives for conventional smoking (46). Perhaps, e-cigarettes or safer alternatives may have been developed earlier as an alternative to conventional tobacco smoking. Bernheim et al. note that public perception regarding the use tobacco changed with the introduction of nicotine replacement therapy, which further echoes the benefits of the implementation of the PP (43). Also, its use may have resulted in a call for removal of cigarettes from the marketplace when multiple ill effects were observed through the Surgeon General Reports, health care, and individual lawsuits against the tobacco industry, which were prevalent as early as $1954(21,22)$.

The PP helps link "uncertain scientific information" to "political responsibility" in an effort to prevent poor health outcomes (13). The public should not be required to bear the proof of the negative effects of tobacco use; the tobacco industry should bear the proof. Moreover, the use of the PP calls for open and democratic decision-making for all stakeholders (12). Social responsibility may result in reduced political and tobacco industry domination of the issue, as well as more public and stakeholder participation to prevent further tobacco-related risks. Putatively, if the PP had been applied in regards to the uncertain risk of tobacco smoking, smoking may have been banned entirely, lives saved, tobaccorelated diseases prevented, and health-care costs reduced.

\section{SHIFTING FROM PAST POLICY TO FUTURE POLICY}

In conclusion, the PP should be applied to e-cigarettes in order to understand the potential benefits and/or long-term consequences of e-cigarette use since currently the scientific research data are inconclusive and regulation virtually non-existent. Use of the PP as a tool will benefit public health policy-makers as they consider the inherent political and ethical dilemmas concerning population health related to e-cigarette use by examining evidence on safer alternatives. ${ }^{2}$ At the state and local levels, existing smoking bans can be amended to include the prohibition of e-cigarettes in public places, and minimum age limits for purchasing e-cigarettes established or raised. On the national level, agencies should prioritize e-cigarette research, regulate advertising and marketing practices, call for premarket regulation, as well as require product labeling in order to educate consumers concerning the potential health risks of e-cigarette use. A proactive and preventive rather than a reactive approach is required to address human activities resulting in health risks. Policy-makers must speak for those without voices, consumers must hold manufacturers ethically accountable, and public health leaders must demand health equity for all.

\section{AUTHOR CONTRIBUTIONS}

$\mathrm{AB}$ : contributed by content development of the perspectives paper along with substantial writing and editing of the paper. $\mathrm{JH}$ and LP: provided substantial input to the content of the paper and reviewed and edited it prior to submission.

${ }^{2}$ The following recommendations are not necessarily those of the authors, nor are they exhaustive or comprehensive of all the potential means of applying the Precautionary Principle to address the impending electronic cigarette crisis. 


\section{REFERENCES}

1. Institute of Medicine. Summary. In: Bonnie RJ, Stratton K, Kwan LY, editors. Public Health Implications of Raising the Minimum Age of Legal Access to Tobacco Products. Washington, DC: The National Academies Press (2015). $360 \mathrm{p}$.

2. U.S. Food and Drug Administration. Summary of Results: Laboratory Analysis of Electronic Cigarettes Conducted by FDA. Public Health Focus. Silver Spring, MD: U.S. Department of Health and Human Services (2009).

3. Dutra LM, Glantz SA. Electronic cigarettes and conventional cigarette use among US adolescents: a cross-sectional study. JAMA Pediatr (2014) 168(7):610-7. doi:10.1001/jamapediatrics.2013.5488

4. King BA, Patel R, Nguyen K, Dube SR. Trends in awareness and use of electronic cigarettes among U.S. adults, 2010-2013. Nicotine Tob Res (2015) 17(2):219-27. doi:10.1093/ntr/ntu191

5. U.S. Food and Drug Administration. Electronic Cigarettes (E-Cigarettes). Public Health Focus. Silver Spring, MD: U.S. Department of Health and Human Services (2014).

6. Adkison SE, O’Connor RJ, Bansal-Travers M, Hyland A, Borland R, Yong $\mathrm{H}-\mathrm{H}$, et al. Electronic nicotine delivery systems: international tobacco control four-country survey. Am J Prev Med (2013) 44(3):207-15. doi:10.1016/j. amepre.2012.10.018

7. Grana RA, Popova L, Ling PM. A longitudinal analysis of electronic cigarette use and smoking cessation. JAMA Intern Med (2014) 174(5):812-3. doi:10.1001/jamainternmed.2014.187

8. Siegel MB, Tanwar KL, Wood KS. Electronic cigarettes as a smoking-cessation tool. Am J Prev Med (2011) 40(4):472-5. doi:10.1016/j. amepre.2010.12.006

9. Waghel RC, Battise DM, Ducker ML. Effectiveness of electronic cigarettes as a tool for smoking cessation or reduction. J Pharmac Technol (2015) 31(1):8-12. doi:10.1177/8755122514547641

10. Rath JM, Villanti AC, Abrams DB, Vallone DM. Patterns of tobacco use and dual use in US young adults: the missing link between youth prevention and adult cessation. J Environ Public Health (2012) 2012:679134. doi:10.1155/2012/679134

11. Leventhal AM, Strong DR, Kirkpatrick MG, Unger JB, Sussman S, Riggs NR, et al. Association of electronic cigarette use with initiation of combustible tobacco product smoking in early adolescence. JAMA (2015) 314(7):700-7. doi:10.1001/jama.2015.8950

12. Raffensperger C, Tickner J. To forsee and to forestall. In: Bayer R, Gostein LO, Jennings B, Steinbock B, editors. Public Health Ethics: Theory, Policy, and Practice (Chap. 20), New York: Oxford University Press (2007). p. 312-26.

13. Martuzzi M, Tickner J. The Precautionary Principle: Protecting Public Health, the Environment and the Future of Our Children. Copenhagen: WHO Regional Office for Europe (2004).

14. Science \& Environmental Health Network, editor. Precautionary principle. Wingspread Conference on the Precautionary Principle (1998). The Johnson Foundation at Wingspread.

15. O'Riordan T, Cameron J. Interpreting the Precautionary Principle. London: Earthscan Publications Limited (2004). p. 315.

16. Noon BR. The Greatest Good for the Greatest Number. Denver Post (2009); Sect. Headlines.

17. Kannan PM. The precautionary principle: more than a Cameo appearance in United States environmental law? William Mary Environ Law Policy Rev (2007) 31(2):409.

18. ICIS News. Court to Hear Challenge to San Francisco BPA Ban. Houston: Reed Business Information (2006).

19. Massey RI, Tenney H, Harriman E. Higher hazard substances under the Massachusetts toxics use reduction act: lessons from the first four years. New Solut (2011) 21(3):457-76. doi:10.2190/NS.21.3.k

20. Fink S. Crisis Management: Planning the Inevitable. New York: AMACOM Press (1986).

21. United States surgeon general's advisory committee on smoking and health USPHS, and office of the surgeon general. Smoking and Health: Report of the Advisory Committee to the Surgeon General of the Public Health Service.
U.S. Department of Health, Education, and Welfare. Washington, DC: U.S. Government Printing Office (1964). p. 5-387.

22. Public Broadcasting Services. Inside the Tobacco Deal (2014). Available from: http://www.pbs.org/wgbh/pages/frontline/shows/settlement/

23. Quinn MJ, Mujtaba BG, Cavico FJ. Global tobacco sales dilemmas: the clash of freedom and markets with morality and ethics. J Business Stud Q (2011) 2(2):107-24.

24. Schick S, Glantz S. Scientific analysis of second-hand smoke by the tobacco industry, 1929-1972. Nicotine Tob Res (2005) 7(4):591-612. doi:10.1080/14622200500185082

25. Centers for Disease Control and Prevention. Tobacco use - United States, 1900 1999. Morb Mortal Wkly Rep (1999) 48(43):986-93. doi:10.2307/23310235

26. Dictionary of American History. Tobacco Industry. Farmington Hills, MI: The Gale Group Inc (2003).

27. Barnes DE, Bero LA. Industry-funded research and conflict of interest: an analysis of research sponsored by the tobacco industry through the Center for Indoor Air Research. J Health Polit Policy Law (1996) 21(3):515-42. doi:10.1215/03616878-21-3-515

28. PR Newswire DJ. International Policy Conference on Children \& Tobacco; Brown \& Williamson's Reasons Why Children Start Smoking. New York City: NEWSEDGE LAN (1999). p. 1-4.

29. Prybil L, Ackerman K, Hastings D, King J. The Evolving Accountability of Nonprofit Health System Boards. Chicago: Center for Healthcare Governance (2013).

30. Schroeder SA. Tobacco control in the wake of the 1998 master settlement agreement. N Engl J Med (2004) 350(3):293-301. doi:10.1056/ NEJMsr031421

31. Turning Point Centers. HAWAII Raises Legal Smoking Age to 21 (2015). Available from: http://turningpointcenters.com/blog/ hawaii-raises-legal-smoking-age-to-21/

32. Centers for Disease Control and Prevention. Smoking and Tobacco Use (2014). Available from: http://www.cdc.gov/tobacco/data_statistics/fact_sheets/ index.htm

33. San Francisco Commission on the Environment. San Francisco Precautionary Principle Ordinance: Three-Year Report. San Francisco: Commission on the Environment (2006).

34. Centers for Disease Control and Prevention. The Socio-Ecological Model: A Framework for Prevention. Atlanta, GA: U.S. Department of Health and Human Services (2009). Available from: http://www.cdc.gov/violenceprevention/overview/social-ecologicalmodel.html

35. Hart PT, Irving L. Janis' victims of groupthink. Polit Psychol (1991) 12(2):24778. doi:10.2307/3791464

36. Keeney RL, Winterfeldt DV. Appraising the precautionary principle - a decision analysis perspective. J Risk Res (2001) 4(2):191-202. doi:10.1080/13669870010027631

37. Goldstein BD. The precautionary principle also applies to public health actions. Am J Public Health (2001) 91(9):1358-61. doi:10.2105/AJPH.91.9.1358

38. Kriebel D, Tickner J. Reenergizing public health through precaution. Am J Public Health (2001) 91(9):1351-5. doi:10.2105/AJPH.91.9.1351

39. Zhu S-H, Sun JY, Bonnevie E, Cummins SE, Gamst A, Yin L, et al. Four hundred and sixty brands of e-cigarettes and counting: implications for product regulation. Tob Control (2014) 23(Suppl 3):iii3-9. doi:10.1136/ tobaccocontrol-2014-051670

40. Williams M, Villarreal A, Bozhilov K, Lin S, Talbot P. Metal and silicate particles including nanoparticles are present in electronic cigarette cartomizer fluid and aerosol. PLoS One (2013) 8(3):e57987. doi:10.1371/journal. pone.0057987

41. Korioth T. E-Cigarettes Easy to Buy, Can Hook Kids on Nicotine. AAP News (2013).

42. Centers for Disease Control and Prevention. Press Release: E-Cigarette Use More Than Doubles among U.S. Middle and High School Students from 2011-2013. Atlanta, GA: United States Department of Health and Human Services (2013).

43. Bernheim RG, Childress JF, Bonnie RJ, Melnick AL. Essentials of Public Health Ethics. Burlington, MA: Jones and Bartlett (2015). 
44. Marynak K, Holmes CB, King BA, Promoff G, Bunnell R, McAfee T. State laws prohibiting sales to minors and indoor use of electronic nicotine delivery systems - United States, November 2014. MMWR Morb Mortal Wkly Rep (2014) 63(49):1145-50.

45. Heath C, Heath D. Switch: How to Change Things When Change Is Hard. New York, NY: Broadway Books (2010).

46. Patient-Centered Outcomes Research Institute (PCORI). Research \& Results: Smoking Cessation Versus Long-Term Nicotine Replacement among High-Risk Smokers. Patient-Centered Outcomes Research Institute (2013). Available from: http://www.pcori.org/research-results/2013/ smoking-cessation-versus-long-term-nicotine-replacement-among-high-risk
Conflict of Interest Statement: The authors declare that the research was conducted in the absence of any commercial or financial relationships that could be construed as a potential conflict of interest.

Copyright (C) 2016 Bush, Holsinger and Prybil. This is an open-access article distributed under the terms of the Creative Commons Attribution License (CC BY). The use, distribution or reproduction in other forums is permitted, provided the original author(s) or licensor are credited and that the original publication in this journal is cited, in accordance with accepted academic practice. No use, distribution or reproduction is permitted which does not comply with these terms. 